\title{
Balatlar Kilisesi'nde ileri düzey biparietal osteodistrofi örneği
}

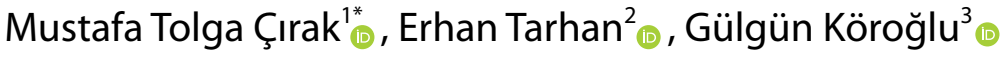 \\ ${ }^{1}$ Doç. Dr. | Hitit Üniversitesi, Antropoloji Bölümü, Çorum - Türkiye \\ ${ }^{2}$ Dr. Arş. Gör. | Hitit Üniversitesi, Antropoloji Bölümü, Çorum - Türkiye \\ ${ }^{3}$ Prof. Dr. | Mimar Sinan Güzel Sanatlar Üniversitesi, Sanat Tarihi Bölümü, İstanbul - Türkiye
}

* Sorumlu Yazar / Corresponding Author: Mustafa Tolga Çırak Hitit Üniversitesi,

Fen Edebiyat Fakültesi, Antropoloji Bölümü İkbalkent Kampüsü, Ulukavak Mah. Çiftlik Çayırı Cad. 45 Çorum / Türkiye E-posta: mustafatolga@yahoo.com

Alındı/Received: 20 Mayıs / May 2021 Düzeltildi/Revised: 9 Aralık / December 2021 Kabul/Accepted: 10 Aralık / December

Öz

$\mathrm{Bu}$ çalş̧mada, Karadeniz'in önemli antik kentlerinden birisi olan Sinop'ta Balatlar Kilise popülasyonu içerisinde 2006 yllında tespit edilen ve 18. yüzyıla ait olduğu düşünülen bir kafatası incelenmiştir. Yapılan makroskobik ve tomografik incelemelerde, ileri erişkin bu bireyin 3. derece bilateral osteodistrofiye sahip olduğu anlaşılmıştır. Simetrik biçimde parietalin her iki yanında yer alan bu lezyon, özellikle sağ parietalde yer yer kemik dokuyu tamamen ortadan kaldırmıştır. Bu durumun, bireyde ciddi hayati bir tehlike oluşturduğu düşünülmektedir. Bilateral osteodistrofinin etiyolojisi net olmamakla birlikte yaşlıllgğa bağh etkenlerin önemli rol oynadığı belirtilmektedir. Bilateral osteodistrofinin bu bireyde gözlemlenmesinin nedeninin ise yaşa bağlı gelișen osteoporoz olduğu düşünülmektedir. Antropolojik çalışmalarda oldukça az rastlanan bu patolojinin Anadolu'daki nadir örneklerden biri olması ve paleopatoloji literatürüne katkı sağlaması açısından önemi büyüktür.

Anahtar Sözcükler: Balatlar Kilisesi, Geç Osmanlı Dönemi, paleopatoloji, biparietal osteodistrofi

\section{Giriş}

Nadir görülen paleopatolojik oluşumlardan birisi olan bilateral parietal incelme (biparietal osteodistrofi), parietal kemiğin çift yönlü kemik kaybına bağlı olarak incelmesi, yer yer de kaybolmasıdır (Resim 1). Bilateral incelme için birçok sinonim tanım kullanılmıştır: involutionskrankheit, malum senile biparietale, senile atrophy, biparietal incelme ve biparietal osteodystrophy en çok kullanılan isimlerdendir (Cederlund vd., 1982). Parietal incelmenin etiyolojisi birçok çalışmada "belirsiz" olarak verilmiştir (Cederlund vd., 1982). Bazı araştırmacılar bunun diploenin displazisi veya gelişimsel anomali olduğunu düşünürken, bazı yazarlar farklı orijinli osteoporosisin göstergesi olduğunu düşünmektedir (Camp ve Nash, 1944; Epstein, 1953; Dutta, 1969). Cederlund ve ekibi (1982) hastalığın konjenital

\section{A case of advanced stage biparietal osteodystrophy in the Balatlar Church Abstract}

In this study, a skull found in 2006 that belongs to the Balatlar Church population in Sinop, which is one of the important ancient cities of the Black Sea and is thought to belong to the 18th century, was examined. In the macroscopic and tomographic examinations, it was revealed that the older adult individual had a pathology called 3rd degree Bilateral Osteodystrophy. Located symmetrically on the both sides of the parietal bones, this lesion completely removed some bone tissue, especially on the right parietal. This incidence is thought to pose a serious life-threatening situation to the individual. Even tough the etiology of bilateral osteodystrophy is not clear, it is stated that the factors related to aging play an important role. The reason for the occurrence of bilateral osteodystrophy in this individual is thought to be the age-related osteoporosis. This pathological lesion, which is rarely encountered in anthropological studies, is of great importance in terms of being one of the rare examples in Anatolia and contributing to the paleopathology literature.

Key Words: Balatlar Church, Late Ottoman period, paleopathology, biparietal osteodystrophy

olmadığına işaret eden, ilerleyici bir incelmenin gözlemlendiği birkaç vakayı yayımlamışlardır.

Parietal kemiklerin bilateral incelmesi, arkeolojik toplumlara ait iskelet materyallerde çok nadir tespit edilebilen bir patolojidir. Gerek dünya genelinde gerek ise antik Anadolu toplumları üzerinde yürütülen arkeolojik kazılarda ele geçmiş birçok iskelet kalıntısının varllğına ve bunların paleopatolojik çalışmalarının bolluğuna rağmen, biparietal osteodistrofi vakası çok az sayıda tanımlanmıştır. Bu nedenle durumun antik dönemlerdeki coğrafi dağılımına dair bilgiler oldukça sınırlı kalmıştır. Avrupa, Amerika, Afrika ve Avustralya'dan nadir vakalar yayınlanmıştır (Smith, 1907; Brothwell, 1967; Lodge, 1967; Dutta, 1969; Arnaud ve Arnaud, 1976; Mallegni, 1977; Breitinger, 1982; Campillo, 1996; Henneberg vd., 2002). 


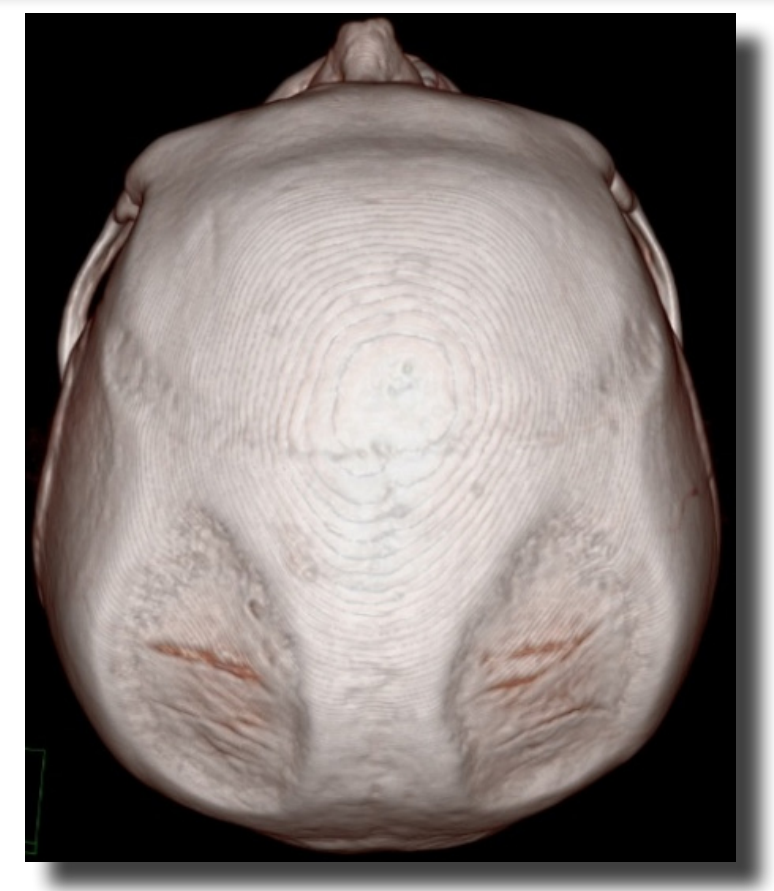

Resim 1. 70 yassinda bir kadin kafasinda biparietal osteodistrofi (Cuete, 2016'dan uyarlama)

Parietal incelme olgusunun varlığına ilk olarak 18. yüzyılda değinilmisstir (Sandifort, 1783). 19. yüzyılda ise bu konu daha ciddi bir ilgi görmüștür (Rokitansky, 1844; Virchow, 1853). Bu konudaki ilk radyolojik bulgular ise 1926'da tanımlanmıştır (Casati, 1926). Günümüzde ileri görüntüleme tekniklerinin gelişmesi ile birlikte daha yoğun biçimde parietal incelme örneklerine rastlanilmaktadır (Resim 2). Greig (1926), Wilson (1944) ve Bruyn ve Bots (1978) tarafindan ise literatürün kapsamlı incelemeleri bildirilmiştir.

Çalışmanın konusunu Sinop Balatlar Kilisesi'nde özel bir mekân olan "kemiklik"te tespit edilen 359 numaralı bir bireyin parietal bölgesinde meydana gelmiş kemik doku incelmesi ve olası sebepleri oluşturmaktadır. Çalışma ile Antik Anadolu Toplumlarında nadir görülen bilateral parietal incelme (bilateral osteodistrofi) vakalarına yeni, özel bir örnek literatüre kazandırılması amaçlanmaktadır. Eski Anadolu toplumları üzerinde yapılan patoloji çalışmalarında genellikle bu lezyon, osteoporoz olarak tanımlanmıştır. Yapılan bu çalışma ile sonraki çalsşmalarda bu lezyonun spesifik isimle (biparietal osteodistrofi) anılması için önemli bir literatür sunmaktadır.

\section{Gereç ve yöntem}

Balatlar Kilisesi olarak tanınan yapı kalıntısı Sinop'un Ada Mahallesi'nde yer almaktadır. Tarihî yapı kalıntısı şehrin merkezinde bulunduğundan, etrafi yeni yapilar tarafindan kuşatılmıştır (Resim 3). 2010 yılından bu yana T.C. Bakanlar Kurulu Kararı, T.C. Kültür ve Turizm Bakanlı̆̆g'nın izinleriyle Mimar Sinan Güzel Sanatlar Üniversitesi Fen Edebiyat Fakültesi Sanat Tarihi

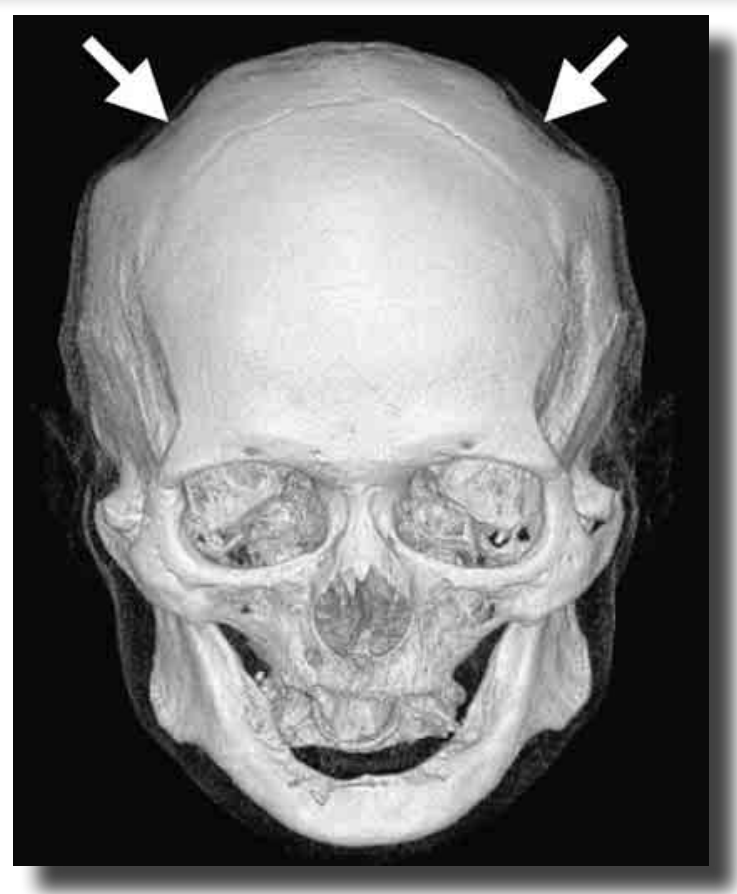

Resim 2. Biparietal osteodistrofinin 3 boyutlu görünümü

(Takata vd., 2008)

Bölümü'nden Prof. Dr. Gülgün Köroğlu Başkanlığında bir ekip tarafindan sistemli kazı çalışmaları devam etmektedir. Yapı kalıntısı Geç Helenistik, Roma, Bizans, Selçuklu ve Osmanlı dönemlerine ait kullanım evrelerini barındırmasıyla, Anadolu'daki önemli kalıntılardan biridir.

Daha eski kalıntılar üzerine Roma Dönemi'nde inşa edilen hamam, sonraki dönemlerde farklı işlevlerle kullanılmıştır. Geç Osmanlı Dönemi'nde burada Tanrı Anası Meryem'e adanmış şehrin önemli bir manastırı kurulmuştur (Köroğlu 2013). Kilisenin iç kısmı ve çevresi 17. yüzyıldan 20. yüzyılın ilk çeyreğine kadar geçen süreçte mezarlık alanı olarak kullanılmıştır (Resim 4).

Çalışmanın materyalini Sinop Balatlar Kilisesi 2016 yılı çalışmalarında ele geçen bir kafatası oluşturmaktadır Çalışmaya konu olan kafatası, Balatlar Kilisesi'nin kemiklik diye tabir edilen 6 nolu mekândan ele geçmiştir (Resim 5). Bu materyalin yalnızca kafatasının cavea kısmı mevcut iken, bulunduğu alandan dolayı, bireye ait başka bir vücut iskeletine erişilememiştir. Bunun nedeninin ise ölen önemli kişilerin sonraki dönemlerde mezarı açılarak kafataslarının kemiklik denen bu özel alanda muhafaza edilmek istenmesi olduğu düşünülmektedir. Kafatası üzerinde, bireyin sosyal statüsüne uygun olarak fes ile gömülmesi neticesinde kırmızı kumaş izleri mevcuttur. Kafatası üzerinde yapılan Antropolojik değerlendirmelerde süturlardan yaşlandırma yapılarak bireyin ileri erişkin (55+ yaş) erkek birey olduğu tespit edilmiştir. Kafatasının 18. yüzyılda yaşamış, Ortodoks bireye ait olduğu düşünülmektedir. Kafatasında supraorbital torus, orbitanın şekli, frontal 


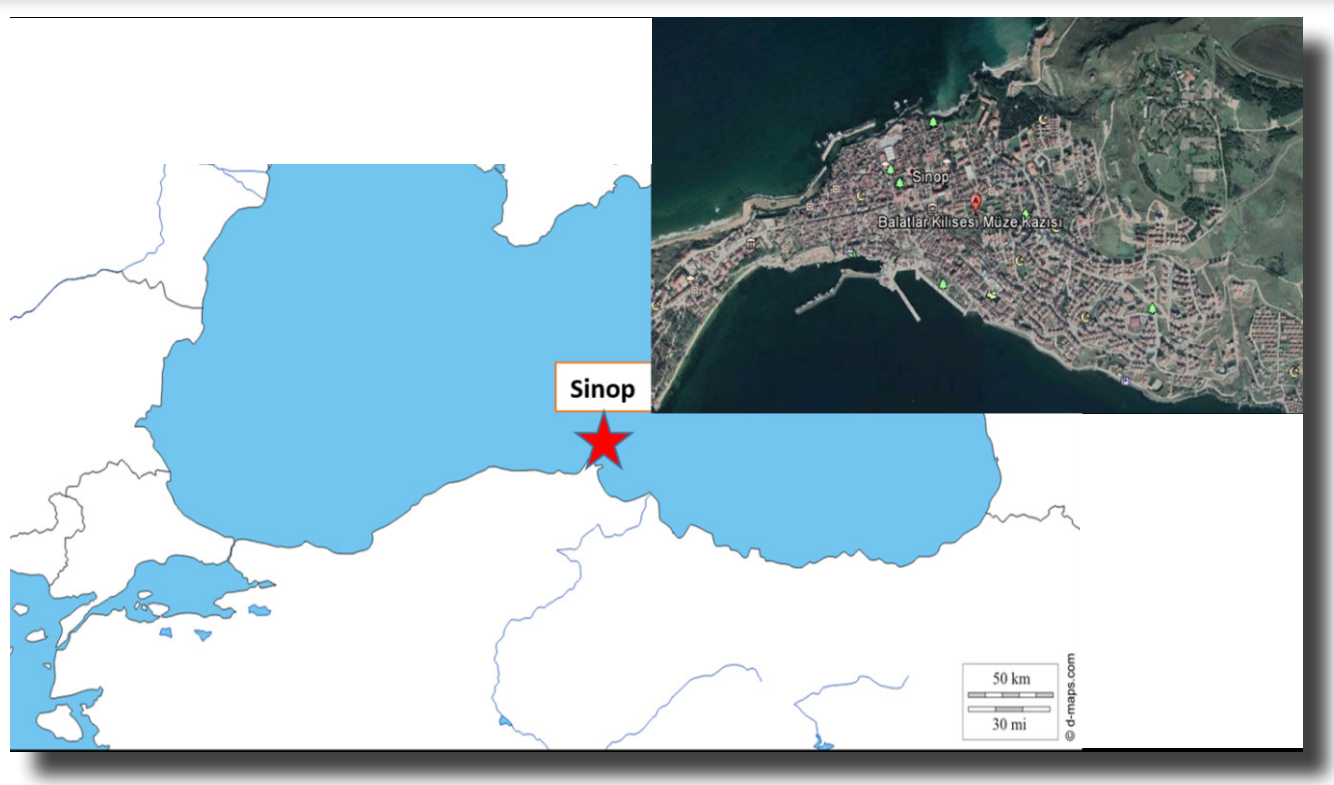

Resim 3. Sinop'un ve Balatlar Kilisesi'nin konumu (Haritalar d-maps.com ve Google Earth'ten alınmıstır)

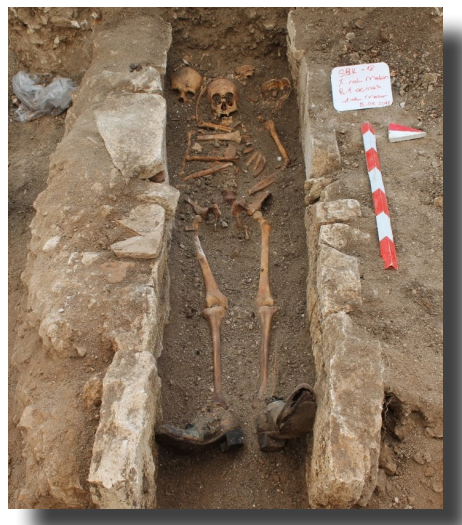

Resim 4. Balatlar Kilisesi Geç Osmanlı Dönemi bir Ortodoks Mez̧ar

bölge, glabella, nuchal crest gibi noktalara bakılarak çalışmaya konu kafatasının erkek bireye ait olduğu tespit edilmiştir. Yaşlandırma ve cinsiyet belirleme Workshop of European Anthropologists (1980), Krogman ve İşcan, (1986), Ubelaker, (1989), White ve ekibinin (2012) yaş ve cinsiyet belirleme kriterleri ile yapılmıştır. Çalışma konusu kafatasının elde edildiği kemiklik alanda yapılan çalışmada 18 . yüzyıla tarihlenen seramikler ve eşyalar iskeletlerin yanında ele geçirilmiştir. Bu sebeple çalışma materyalinin de 18. Yüzyıla ait olduğu sonucuna varılmıştır. İncelemesi yapılan kafatasının 3 boyutlu bilgisayarlı tomografik görüntülemesi, Hitit Üniversitesi Erol Olçok Eğitim ve Araştırma Hastanesi Radyoloji Bölümünde gerçekleștirilmiştir.

Parietal incelme aşamaları kemiğin kalınlık derecesine göre Cederlund ve ekibi (1982) tarafindan sınıflandırılmıştır. Bu çalışmada, parietal incelmenin sınıflandırmasında bu sınıflama baz alınmıştır:

- Evre 1. Minimum kriterler görünür. Anteroposterior görünümde üst parietal bölgede hafif, ancak kesin düzleșme veya oluklaşma gözlemlenir. Parietal kemiğin kalınlığının en fazla yarısında kayıp

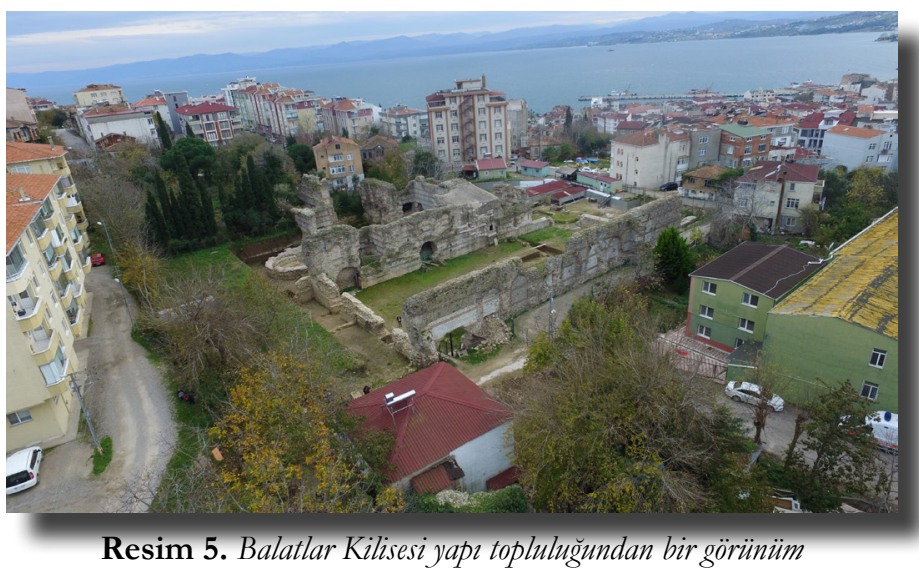

gözlenir. Lateral görünümde hafif radyolüsen (röntgendeki koyu-siyah görünüm) gözlemlenir.

- Evre 2. Kemik kalınlığının yarısından daha fazla kayb1 ile anteroposterior görünümde kayda değer düzleşme ya da oluklaşma görülür, ancak diploe lezyonun her bölgesinde bir dereceye kadar korunmuş şekildedir.

- Evre 3. Bölgedeki diploe ve diş katmanın toplam kemik kaybı en fazla etkilenmiştir.

\section{Bulgular}

Kafatas1 üzerinde yapılan ilk inceleme, makroskobik inceleme olmuştur. 359 kod numarası verilen ileri erişkin erkek bireye ait parietal kemiğin her 2 yanında gözle görülecek düzeyde, kemiğin tonozlu yapısında bariz incelme olduğu gözlemlenmiştir. Bu patolojik lezyon, daha çok yaşlı bireylerde gözlemlenen "biparietal osteodistrofi” olarak tanımlanmıştır (Resim 6).

Bireyin parietal kemiklerindeki belirgin incelmenin yanı sira frontal kemiğinde de ciddi bir deformasyon olduğu gözlemlenmiştir. $\mathrm{Bu}$ sebeple biparietal osteodistrofiye sebebiyet veren şeyin, ilerleyen yaşa bağlı oluşan osteoporoz olduğu tahmin edilmiştir. 


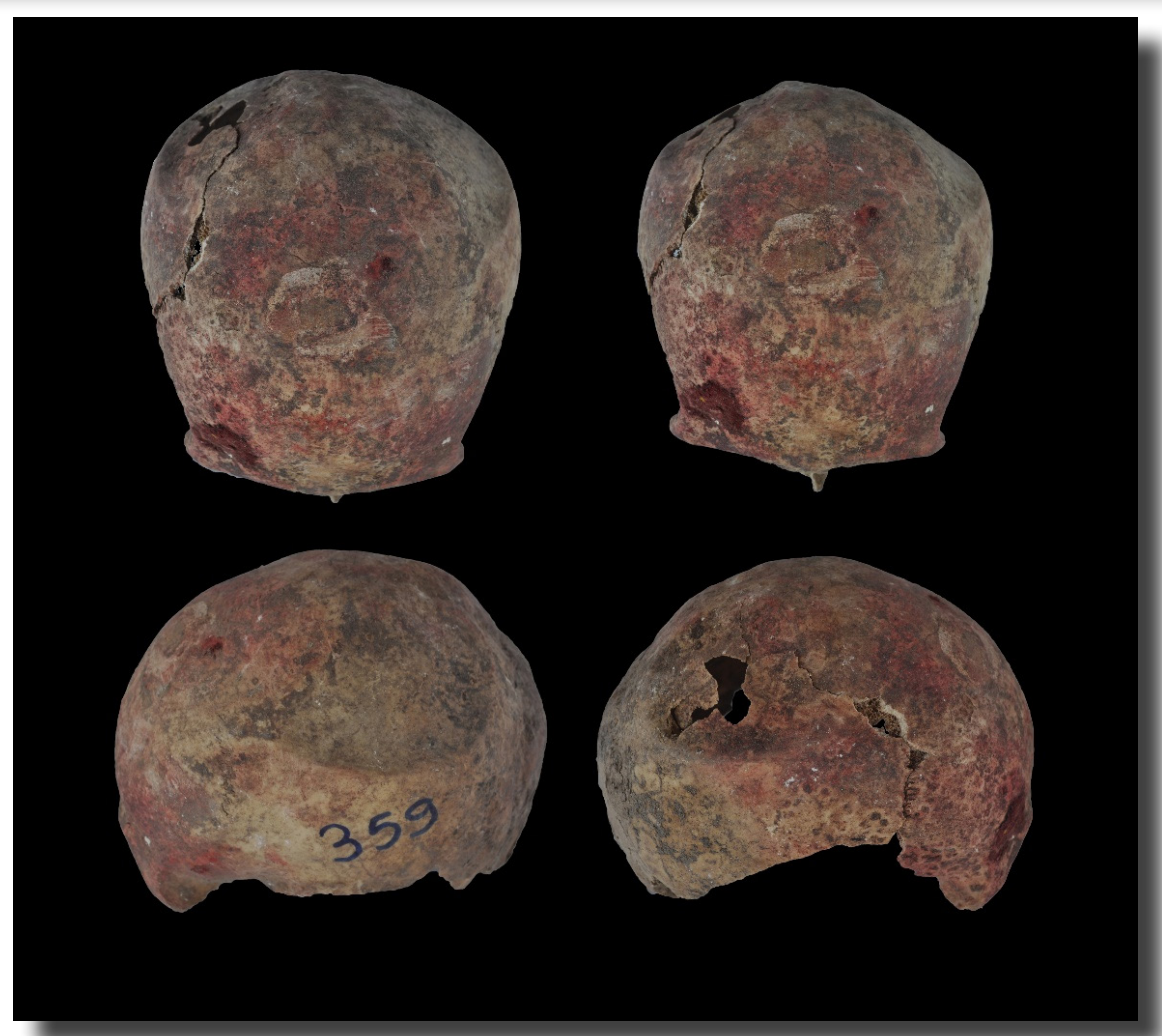

Resim 6. Biparietal osteodistrofiye sahip Balatlar Kilisesi 359 numarah kafatası

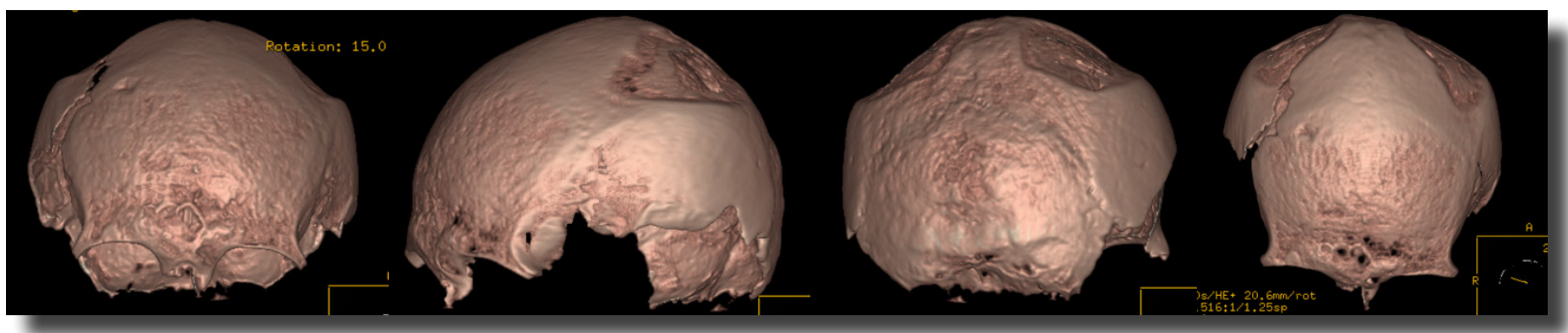

Resim 7. 359 numaral kafatasmm dört yönden bilgisayarl tomografi görüntüleri.

Strasyyla anterior, sol anterolateral, sağ posterlateral ve anterosuperior yönler.

Bireyin parietal kemiklerinde dış katman ve diploe yok olmuş, iç katman varlı̆̆ını korumuştur. Özellikle bir bölgede tamamen iç katman da yok olarak kafatasında bir boşluk oluşmuştur. Bu, Cederlund ve ekibinin (1982) çalışmalarında verdikleri incelme aşamalarından evre 3'e tekabül etmekte olup, belirgin incelme olarak değerlendirilmektedir. Bu bireydeki çift taraflı incelme, her iki yönde eşit oluşmamıştır; literatürdeki pek çok örnekte olduğu gibi, bir yön incelmeden daha fazla etkilenmiştir. Bu bireyin sağ parietal bölgesi incelmeden daha fazla etkilenmiştir ve yer yer kemik doku ortadan kaybolmuştur. İncelmenin bulunduğu kenarlar bir raf (eşik) şekli sergilemektedir. Lezyon bölgesinde bir krater görünümü meydana gelmiştir (Resim 7). Kafatasına önden bakıldığında parasagittal bir crest görünümü oluşmuş durumdadır. Aynı zamanda bu bireyde az miktarda cribra orbitalia da saptanmıştır. Tüm bu sonuçlara ek olarak, yapılan radyolojik görüntülemeler sayesinde patoloji çok daha net bir şekilde tanımlanmışır (Resim 8).

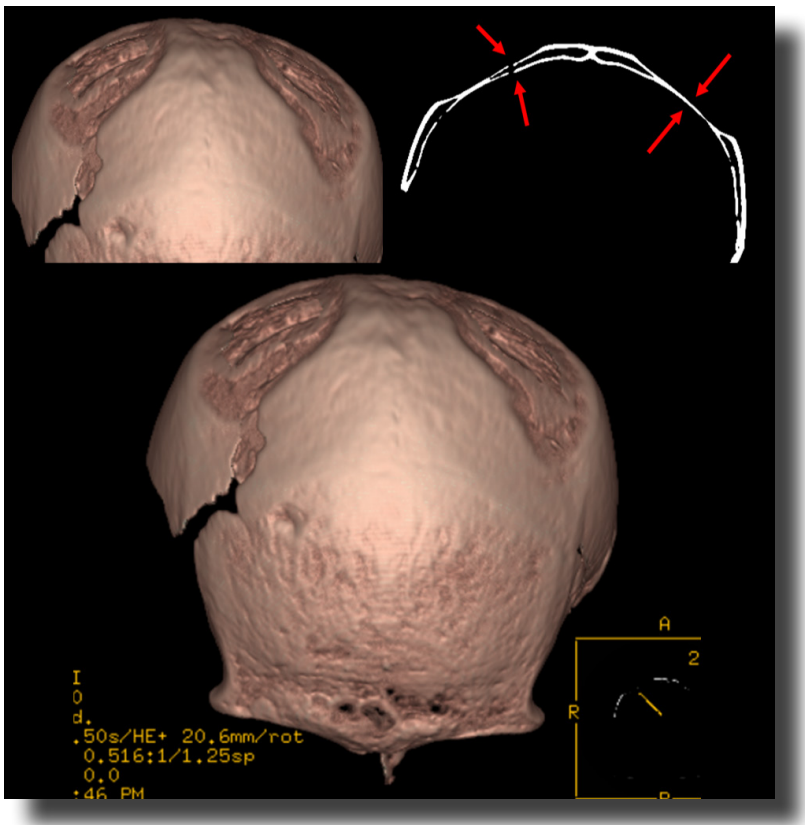

Resim 8. 359 numaral kafatasinn 3 boyutlu bilgisayarl tomoografi görüntüsü. Kırmı̨̨ oklar incelmelerin olduğu yeri belirtiyor. 


\section{Tartışma}

Parietal incelme vakalarına dair ilk doğru tanımlamanın 1783 yilında Sandifort tarafindan yapıldığ 1 düşünülmektedir. Mısır mumyalarında (Smith, 1907) ve Hindistan'da 4300 yıllık Bronz Çağı kafatasında da parietal incelme vakaları tanımlanmıştır (Dutta, 1969). Bilateral incelmede, lateral çıkıntı ve superior posterior bölgelerdeki parietal kemikler çok ince, kırılgan ve yar1 saydam özellikleri taşır (Mann ve Hunt, 2012). Bruyn ve Bots (1978) yaptıkları detaylı literatür çalışmasında, vakanın anatomik bir varyasyon değil, patolojik bir lezyon olduğunu belirtmişlerdir. Lezyonun tüm enlemlerde görüldüğünü, yaygınlığının ise $\% 0,4$ ile $\% 0,5$ arasında olduğunu iddia etmişlerdir. Genellikle 60 yaşından sonra ve çoğunlukla kadınlarda görüldüğünü (cinsiyet oranı, erkek:kadın $=1: 2,5$ ) aktarmışlardır. Bruyn ve Bots'un (1978) bu çalışmalarına göre Histolojik kanıtlar, dış katmanın erozyonunun, diploenin yeniden oluşmasıyla dengelendiğini ve sonrasında diploe kaybı ile sonuçlandığını göstermiştir.

1000 kafatasını inceleyen Carriere vakanın sıklığını $\% 0,4$ olarak bildirmiştir (Carriere, 1874). Lodge ise bu oranın çok yüksek olduğunu düşünmüştür (Lodge, 1975). Bazı yazarlar bu durumu gelişimsel bir kusur olarak tanımlarken (Lodge, 1975; Barnes, 1994), diğer araştırmacılar ise yaşlı bireylerde ilerlemiş osteoporoz ile parietallerin incelmesini ilişkilendirmiştir (Epstein, 1953; Ortner ve Putschar, 1985; Aufderheide ve RodríguezMartín, 1998).

Durumun gelişimsel mi, osteoporoz ile mi, yoksa her ikisi ile de mi ilişkilendirileceğinin belirsiz olduğunu aktaran çalışmalar da mevcuttur (Greig, 1926; Wilson, 1944). Amerika'da 119 radyolojik vaka üzerinde yapılan bir çalışmada Camp ve Nash (1944) parietallerin incelmesinin erkeklerde kadinlardan daha s1k görüldüğünü belirterek, diğer çalışmalardan farklı bir sonuç önermişlerdir. Güncel ve arkeolojik çoğu vakada, parietallerin incelmesi yaşl1lık ile ilişkilendirilmektedir. 30 yaşından küçük bireylerde sadece birkaç vaka bildirilmiştir (Barnes, 1994; Camp ve Nash, 1944).

Cederlund ve ekibi (1982) 14 y1llık periyotta 3636 hastayı çalışmıs (1990'1 erkek, 1646'sı kadın bireyler olmak üzere) ve bunların 86'sında (\%2,37) parietal incelme tespit etmişlerdir Bu çalsşmaya göre, lezyon kadınlarda daha yaygin olmakla birlikte, cinsiyet oranı 1:1,9'dur. Erkek hastaların ortalama yaşı 63 (dağılım 2189 yıl); kadın hastaların ortalama yaşı 72 (dağılım 34-93 yil) olarak belirlenmiştir. Bu hastalardan 25'inin daha önceki kafatası film kayitları da mevcut olup, bunlardan 10 tanesinde ilerleme saptanmıştır (İlerleyici incelmenin gözlemlendiği en kısa süre 2 yıl 3 ay, hastada ilerleme olmadan geçen en uzun süre ise 14 yll 11 ay olarak belirlenmiştir). Yazarlar parietal incelmenin; diploenin displazisi veya bir anatomik varyantı olmadığını, daha ziyade orta yaşlı ve yaşlı insanların yavaş, ilerleyici bir hastalı̆̆1 olduğu sonucuna varmışlardır (Cederlund vd., 1982). Bu çalışmaya göre tüm hastalarda, incelme bölgesi tipiktir, yani superior temporal çizginin üstündeki ortaparietal alanın üst kısmında oluşup, parasagittal kemiği sağlam bırakmıştır.

1873'te yaşlı bir kadın birey ve erişkin bir orangutanda rastlanılan bu oldukça nadir görülen durum (Humphry, 1873), etiyolojisi bilinmemekle birlikte yaşa bağlı olarak görülmektedir (Grainger vd., 2001). İlginç bir nokta, incelmenin genellikle parietal foraminay 1 çevreleyen yaklaş1k $1 \mathrm{~cm}$ etkilenmemiş kemik bırakarak, parietal foraminayı korumasıdır (Mann ve Hunt, 2012). Wilson (1944) tarafindan lezyonun karakteristik bölgesi, sagittal sutur ile parietal prominence arasindaki parietal kemikler olarak belirlenmiştir. Humphry (1858) ise benzer şekilde sagittal sutur ile parietal eminence arasinda lezyonun oluştuğuna ve parietal foraminanın kesinlikle etkilenmediğine değinmiştir. İncelme genellikle iki taraflıdır (bilateral), ancak nadiren tek taraflı vakalar da mevcuttur (unilateral) (Wilson, 1947). Bu hastalik genel anlamda yaygın değildir, yaygınlığ $\% 0,25-0,8$ olarak bildirilmiştir (Bruyn ve Bots, 1978). Cederlund ve ekibi (1982) çalışmalarında dağılım oranını \%2,37 olarak belirlemiş ve spesifik olarak aranmadıkça hem klinik hem de radyografik muayenede göz ardı edilmeye müsait, erken bozulmaları (ilk evre) olan birçok vakayı bildirmişlerdir. Çalışmalarına göre hastalarının sadece $\% 0,88$ inde belirgin incelme (evre 2-3) mevcuttur.

Lezyon ağırlıklı olarak sporadik görülmektedir. Yine de otozomal bir iletimin olduğuna değinen çalışmalar familyal oluşumları bildirmiştir: Shepherd (1893) 62 yaşındaki bir kadin ve babasından, Bloch (1897) 86 yaşındaki bir kadın ve anneannesinden, Wilson (1944) 69 yaşında Çinli bir erkek ve 45 yaşındaki oğlundan, Camp ve Nash (1944) 73 yaşındaki bir kadın ve annesinden, Nashold ve Netsky (1959) 24 yaşındaki bir erkekten (tek tarafll olgu) ve kardeşinden (bilateral), Lodge (1967) 80 ve 82 yaşlarında gaz zehirlenmesinden eş zamanlı ölen iki kız kardeşte lezyonun varlığından bahsetmiştir (Bruyn ve Bots, 1978). Literatürden 126 olgu toplayan Bruyn ve Bots (1978), lezyonun kadinlarda 1:2,5 oraninda daha yaygın olduğunu belirtmişlerdir. Bu, Cederlund vd. (1982) çalışmasında verilen 1:1,9 oranına yakın görünmektedir. Ancak, Camp ve Nash, 119 kişilik hasta serisinde bir erkek baskınlığı buldular (Camp ve Nash, 1944). Bu vakaların büyük çoğunluğunun erkeklerde 50 yaşından sonra, kadınlarda 60 yaşın üzerinde görüldüğü fark edilmiştir. Cederlund vd. (1982) ortalama yaş1 erkeklerde 63, kadınlarda 72 olarak belirlemişlerdir.

Etiyolojiyi açıklamak için birçok teori öne sürülmüştür. Kellik, sifilis, yaşlilık, çocuklukta kafa travmas1, kas traksiyonu veya slider galea aponeurotica gibi mekanik faktörler, vasküler değissiklikler, zihinsel 


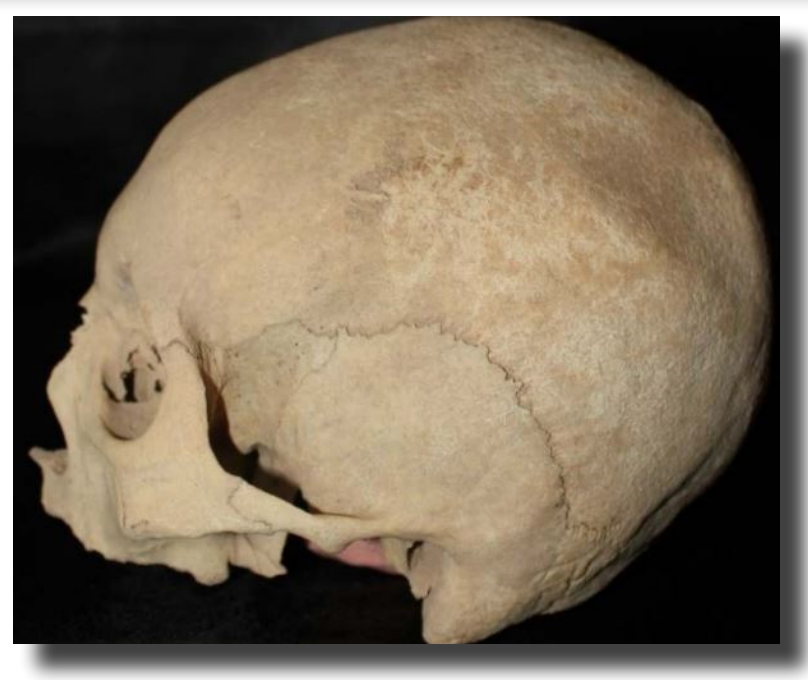

Resim 9. Zeytinliada kafatası örneği (Takunyacıoğlu, 2019)

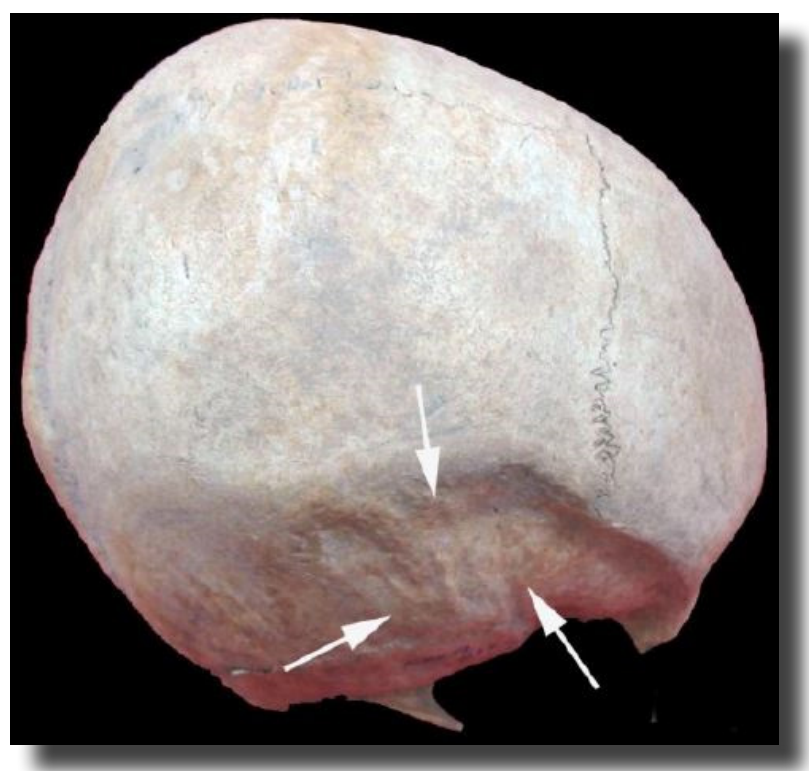

Resim 10. Kelenderis kafatası örneği (Çırak, 2009)

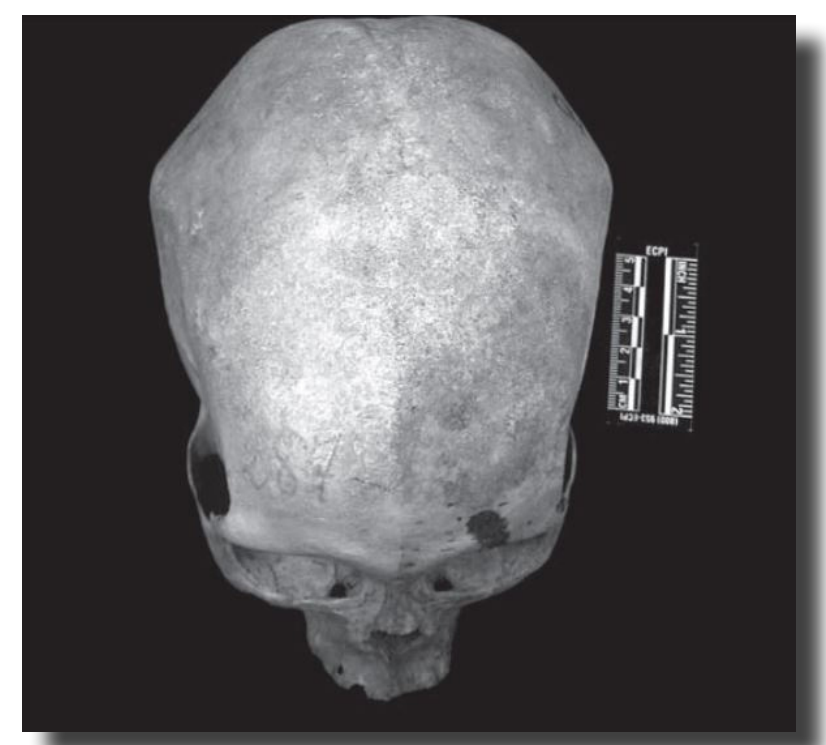

Resim 11. Osmanl Dönemi kafatası örneği (Sağır vd., 2009) bozukluklar ve ağır peruklar giyilmesi gibi etmenlerin tümü incelmede zaman zaman sorumlu tutulmuştur. 26 olgudan oluşan bir raporda hastaların büyük bir yüzdesinde postmenopozal osteoporoz, senile osteoporoz veya idiyopatik osteoporoz bulunmuş ve Epstein (1953), koşullar arasında bir etiyoloji ilişkisi olduğundan şüphelenmiştir. Yine de çalışmaların genelinde, hastaların analizlerinde ortak bir etiyoloji paydası bulunamamıştır. Cederlund ve ekibi (1982) bazı hastalarında hormonal bozukluklar olduğunu ve şaşırtıcı olmayacak şekilde çoğunda osteoporoz olduğunu (çoğunlukla yaşlı kadınlarda) belirtmişlerdir. Anormalliğin muhtemelen diploenin konjenital displazisi olduğunu vurgulayan, statik yapısını vurgulamak için thinning yerine parietal thinness olarak adlandırılması gerektiğine inanan eski çalışmalar mevcuttur (Greig, 1926; Camp ve Nash, 1944; Wilson, 1944). 50 yaşından sonra ortaya çıkan birçok vaka vardır ve bu durum lezyonun konjenital olma ihtimaline karşı net bir şekilde ağır basmaktadır. Steinbach ve Obata 85 yaşında bir kadını belirgin bir şekilde incelmiş parietal kemiklerle tanımladılar (Steinbach ve Obata, 1957). Aynı hastanın 67 yaşındayken alınan kafatası radyografilerine bakıldığında, lezyonun ilerleyici ve muhtemelen sonradan oluşmuş olduğunu kanıtlayan çok hafif parietal incelme gördüler.

Cederlund ve ekibi (1982), en az iki radyografi verisi mevcut olan 25 bireyden 10 tanesinde ilerleme gözlemlediler. Bu vakaların çoğunda, ilerlemenin tespit edilebilmesi için muayeneler arasında uzun bir sürenin (10 hastanın 8'inde yedi yıldan fazla) gerekli olduğuna değinmişlerdir. Bulgularında, parietal kemiklerin bilateral incelmesinin anatomik bir varyant veya konjenital displazi olmadığını, orta yaş ve yaşlılıkta yavaş ilerleyen bir hastalık olduğunu ve kadınlarda erkeklere nazaran daha yaygın olduğunu ileri sürmüşlerdir (Cederlund, 1982).

Yılmaz ve ekibi (2013) vaka çalışmalarında 78 yaşındaki bir kadın bireyde epidural hematoma tespit etmişlerdir. Bu bireyin başını hafif bir şekilde dolaba vurması sonucu (minor travma) baş ağrısı şikâyeti ile hastaneye gitmesini takiben çekilen bilgisayarlı tomografi görüntüleri, bireyin parietalindeki çizgisel kırı̆̆1 ve epidural hematomu ortaya çıkarmıştır. Bireyde biparietal osteodistrofi olduğu ve parietallerinde diş katman ile diploenin yok olduğu da belirtilmiştir (Yılmaz vd., 2013). İlerleyen yaş ile birlikte, yaşanabilecek bu tarz travma vakalarında parietallerin incelmiş olması, bu lezyona sahip bireylerin sağlıklarını ciddi anlamda tehdit edebilecek görüntüdedir.

Zeytinliada kazı çalışmalarında açığa çıkarılan bireylerin birisine ait kafatasında çift tarafle parietal incelme bulgusu tanımlanmıştır (Takunyacıoğlu, 2019). Bahsi geçen çalışmada osteoporoz olarak tanımlanan bu lezyon muhtemel bir biparietal osteodistrofi örneği 
olabilecek görüntüdedir. Çalışmada (Takunyacıoğlu, 2019) verilen kafatası görseline bakıldığında tipik biparietal osteodistrofi görüntüsü mevcuttur ve lezyon bölgesi de diğer biparietal osteodistrofi vakaları ile aynidir (Resim 9).

Kelenderis kazı çalışmalarında açı̆̆a çıkarılan bir bireyde de kafatasında incelme vakası tanımlanmıștır (Günay, 2005; Çırak, 2009). Örnekteki lezyon biparietal atrofi olarak tanımlanmıştır ve buna osteoporozun sebebiyet vermiş olma ihtimali üzerinde durulmuştur (Günay, 2005). Örneğin aşağıdaki görseline bakıldığında (Resim 10) incelmenin tipik biparietal osteodistrofi bölgesinden nispeten farklı olduğu anlaşılmaktadır.

Osmanlı Dönemi iskeletlerini analiz eden Sağır ve ekibi (2009), kafatasının parietalinde çift taraflı incelmeye sahip bir bireyi tanımlamıs ve görselini paylaşmışlardır (Resim 11). Çalışmada Sağır ve ekibi (2009) bireyin osteoporozlu olduğuna değinmişlerdir. Görsele bakıldığında lezyonun biparietal osteodistrofi bulgularındaki tipik bölgede oluştuğu anlaşılmaktadır.

\section{Sonuç}

Sinop Balatlar Kilisesi kazı çalışmalarında ele geçen ve bu çalışmanın materyali olan kafatası buluntusu, ileri erişkin bir erkek bireyde çift taraflı parietal incelme vakasinı (evre 3, son evre) bizlere sunmuştur. Kafatası üzerinde yapılan analizler, CT görüntülerinin de katkılarıla, bireyin patolojik olgularını net bir şekilde açığa çıkarmıştır. Bu bilateral incelme olgusunda bireyin sağ parietal bölgesi daha fazla etkilenmiştir. Çift taraflı incelmeden dolayı parasagittal bir crest oluşumu ve parietal bölgelerde krater oluşumu gözlenmiştir. Frontal bölge lezyonları ile birlikte değerlendirildiğinde, biparietal incelmenin ilerlemiş yaşa bağlı osteoporoz kaynaklı olması muhtemel görünmektedir. Özellikle sağ parietal bölgedeki incelmenin yer yer kemik dokuyu tamamen ortadan kaldırdığ1 tespit edilmiştir. $\mathrm{Bu}$ durumun, birey için hayati risk teşkil ettiği düşünülmektedir. Beyinin incelmenin yoğun olduğu o bölgede dişardan gelecek etkilere karşı korunmasız oluşu, ölüme veya beyin hasarına neden olabilecek sonuçları doğurması kaçınılmazdır. Detaylı tüm analizleri ve tanımlamaları "Bulgular" başlığında yapılmış olan bu bireyde gözlemlenen biparietal osteodistrofi olgusu, bu çalışma ile hem dünya hem de Anadolu toplumları için literatüre kazandırılmış olup, sonraki çalışmalar için de önemli bir karşılaştırma materyali oluşturmaktadır. Zira Sinop Balatlar Kilisesinden elde edilen biparietal osteodistrofi örneği, Antik Anadolu toplumları içerisinde hem makroskobik hem de radyografik olarak tanısı konulmuş en netörneklerden biridir ve dünya arkeolojiliteratüründe son yıllarda çok fazla örneği bulunmamaktadır. Bu örneğin, sonraki paleopatolojik çalışmalarda farkındalık oluşturarak bu patolojinin tanımlanmasında önemli bir referans olması beklenmektedir.

\section{Kaynakça}

Arnaud, G., ve Arnaud, S. (1976). Un nouveau cas d'Amincissement bipariétal symetrique. Bulletins et Mémoires de la Société d'Anthropologie de Paris, 3(1), 3-14. https://doi.org/10.3406/ bmsap.1976.1833

Aufderheide, A. C., ve Rodriguez-Martin, C. (1998). The Cambridge encyclopedia of human paleopathology. Cambridge University Press.

Barnes E. (1994). Developmental defects of the axial skeleton in paleopathology. University Press of Colorado.

Bloch, R. (1897) Familiendisposition bei symmetrischer Atrophie des Schädeldaches. Prager Medizinische Wochenschrift, 22, 147161.

Breitinger E. (1982). Depressio biparietalis circumscripta I. Zwei Falle aus dem Avaren Zeitlichen Gräberfeld von Zwolfaxing bei Wein. Archaeologia Austriaca 66, 141-153.

Brothwell, D. R. (1967). Biparietal thinning in early Britain. D. R. Brothwell DR ve A. T. Sandison (Ed.) içinde, Diseases in antiquity (s. 413-416). Charles C Thomas Publisher.

Bruyn, G. W., ve Bots, G. T. A. M. (1978). Biparietal osteodystrophy. Clinical Neurology and Neurosurgery, 80(3), 125-128. https:// doi.org/10.1016/S0303-8467(78)80035-3

Camp, J. D., ve Nash, L. A. (1944). Developmental thinness of the parietal bones. Radiology; 42(1), 42-47. https://doi. org/10.1148/42.1.42

Campillo, D. (1996). Paleopatologia. Los primeros vestigios de la enfermedad. Fundacion Uriach.

Carriere, J. (1874) C. R. des travaux de la soc. anat. pour l'année 1870 (45e année). Bulletin de la Société anatomique de Paris.

Casati, A. (1926) Die senilen Schadelveranderungen im Röntgenbild. Fortschritte auf dem Gebiet der Röntgenstrablen und der bildgebenden Verfabren, 34, 335.

Cederlund C.-G., Andrén, L., ve Olivecrona, H. (1982). Progressive bilateral thinning of the parietal bones. Skeletal Radiology, 8(1), 29-33. https://doi.org/10.1007/bf00361365

Cuete, D. (2016). Biparietal osteodystrophy. Case study, Radiopaedia. org. Erişim: 10 Aralık 2021, https://doi.org/10.53347/rID$\underline{46109}$

Ç1rak, A. (2009). Kelenderis iskeletlerinin paleoantropolojite analizi ve Anadolu toplumlar arasindaki yeri [Yayımlanmamış doktora tezi]. Ankara Üniversitesi, Sosyal Bilimler Enstitüsü, Ankara.

Dutta, P. C. (1969). Bilateral parietal thinning in Bronze age skull. British Medical Journal, 1, 55. https://doi.org/10.1136/ bmi.1.5635.55

Epstein, B. S. (1953). The concurrence of parietal thinness with postmenopausal, senile, or idiopathic osteoporosis. Radiology, 60(1), 29-35. https://doi.org/10.1148/60.1.29

Grainger, R. G., Allison, D. J., Adam, A., Dixon, A. K. (Eds.) (2001). Diagnostic radiology: a textbook of medical imaging, 4th ed. Churchill Livingstone.

Greig, D. M. (1926) On symmetrical thinness of the parietal bones. Edinburgh Medical Journal, 33(11), 645-671. https://www.ncbi. 
nlm.nih.gov/labs/pmc/articles/PMC5320304/

Günay, I. (2005). Mersin-Kelenderis (19.yy) toplumunun sağhk sorunlar [Yayımlanmamış yüksek lisans tezi]. Ankara Üniversitesi, Sosyal Bilimler Enstitüsü, Ankara.

Humphry, G. J. (1873). Depressions in the parietal bones of an orang and in man. Journal of Anatomy and Physiology, 8(1), 136-141. https://www.ncbi.nlm.nih.gov/labs/pmc/articles/ PMC1319014/

Humphry, G. J. (1858) The human skeleton. Cambridge.

Köroğlu, G. (2013). Sinop Balatlar Kilise 2011 Yılı Kazı Çalışmaları. Kazı Sonuclar Toplantısı, 34(3), 313-324. https://kvmgm.ktb. gov.tr/Eklenti/7335,34kazi3.pdf?0

Krogman, W. M., and İscan, M. Y. (1986). The buman skeleton in forensic medicine, 2 nd edition. Charles $\mathrm{C}$. Thomas.

Lodge, T. (1967). Thinning of the parietal bones in early Egyptian populations and its aetiology in the light of modern observations. D. R. Brothwell ve A. T. Sandison (Ed.) içinde, Diseases in antiquity (s. 405-412). Charles C Thomas Publisher.

Lodge, T. H. (1975) Developmental defects in the cranial vault. The British Journal of Radiology, 48(570), 421. https://doi. org/10.1259/0007-1285-48-570-421

Henneberg, M., Henneberg, R., ve Cipriani, M. (2002). Bilateral symmetrical thinning of the parietals in a female from Santa Venera necropolis of ancient Poseidonia, Italy (5th Century BC). Paleopathology Newsletter 118, 12.

Mallegni, F. (1977). Un Caso dí Assottigliamento Biparíetale Simmetrico in Un Calvario della Necropoli Eneolitico del Gaudo. Atti Societá Toscana di Scienze Naturali, 83, 31-41.

Mann, R. W., ve Hunt, D. R. (2012). Photographic regional atlas of bone disease: a guide to pathologic and normal variation in the buman skeleton, 3rd ed. Charles C Thomas.

Nashold, B. S. ve Netsky, M. G. (1959). Foraminae, fenestrae, and thinness of parietal bone. Journal of Neuropathology \& Experimental Neurology, 18(3), 432-441. https://doi. org/10.1097/00005072-195907000-00005

Ortner, D. J., ve Putschar, W. G. J. (1985). Identification of pathological conditions in buman skeletal remains. Smithsonian Institution Press. https://doi.org/10.5479/si.00810223.28.1

Rokitansky, C. (1844) Handbuch der speziellen pathologischen Anatomie. Braumüller \& Seidel.

Sağır, M., Özer, İ., ve Güleç, E. (2009). Osmanlı dönemi kafataslarının paleopatolojik analizi. Arkeometri Sonuclar Toplantısı, 24, 65-78. http://www.kulturvarliklari.gov.tr/ sempozyum pdf/arkeometri/24 arkeometri.pdf

Sandifort, E. (1783). Exercitationes academicae. Caput quintum. De sinusantii profundo, in utroque osse verticis observato. S and J Luchtmans, Leyden.

Shepherd, F. J. (1893). Symmetrical depressions on the exterior surface of the parietal bones (with notes of three cases). Journal of Anatomy and Physiology, 27(4), 501-504. https://www. ncbi.nlm.nih.gov/labs/pmc/articles/PMC1328301/
Smith, G. E. (1907). The causation of the symaetrical thinning of the parietal bones in Ancient Egyptians. Journal of Anatomy and Physiology, 41(3), 232-233. https://www.ncbi.nlm.nih.gov/ labs/pmc/articles/PMC1289120/

Steinbach, H. L., ve Obata, W. G. (1957) The significance of thinning of the parietal bones. The American Journal of Roentgenology, Radium Therapy, and Nuclear Therapy, 78(1), 39-45.

Takata, S., Takao, S., Yoshida, S., Hayashi, F., ve Yasui, N. (2008). Therapeutic effects of one-year alendronate treatment in three cases of osteoporosis with parietal thinning. The Journal of Medical Investigation, 55(3-4), 297-302. https://doi. org/10.2152/jmi.55.297

Takunyacıoğlu, B. (2019). Zeytinliada insanları ve yaşam biçimleri [Yayımlanmamış yüksek lisans tezi]. Sivas Cumhuriyet Üniversitesi, Sosyal Bilimler Enstitüsü, Sivas.

Ubelaker, D. H. (1978). Human skeletal remains: Excavation, analysis, interpretation. Aldine Publishing Company.

Virchow, R. (1853). Über die Involutionskrankheit (Malum senile) der platten Knochen. Verbandlungen der PhysikalischMedizinischen Gesellschaft zu Würzburg, 354.

White, D. T., Black, M. T., ve Folkens, P. (2012). Human osteology, 3rd edition. Academic Press.

Wilson, A. K. (1944). Roentgenological findings in bilateral symmetrical thinnes of the parietal bones (senile atrophy). Report of a case with a review of the literature. The American Journal of Roentgenology, 51, 685.

Wilson, A. K. (1947). Thinness of the parietal bones. Report of a case having predominantly unilateral involvement. The American Journal of Roentgenology, 58, 724.

Workshop of European Anthropologists (1980). Recommendations for age and sex diagnoses of Skeletons. Journal of Human Evolution, 9(7), 517-549. https://doi.org/10.1016/00472484(80)90061-5

Yılmaz, M. B., Egemen, E., Özbakır, B., ve Tekiner, A. (2013). Epidural hematoma after minor trauma on patient with biparietal osteodystrophy. Journal of Korean Neurosurgical Society, 53(1), 57-58. https://doi.org/10.3340/jkns.2013.53.1.57

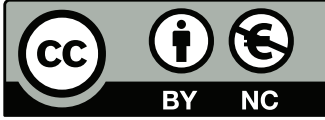

Bu makale Creative Commons Atıf-GayriTicari 4.0 Uluslararası (CC BY-NC 4.0) lisansının hüküm ve şartları altında yayımlanan açık erişimli bir makaledir. 